decided to rationalise the healthcare system without taking much account of the impact of the reforms on its citizens. The dissatisfaction among Croatian citizens with these reforms indicates that decision makers should consider users' opinions during health service reform if they wish to build a system that is not only cost efficient but is also responsive to citizens' needs, expectations, and health status.

Contributors and sources: MM is a medical sociologist who has been analysing health systems reforms over the past 20 years. His primary interest is in health inequalities. SK has been researching patient perspectives and health communication in general. The arguments found in this article are mainly based on published papers on health reform in Croatia and government documents.

Competing interests: None declared.

1 Orešković $\mathrm{S}$. Health system reorganization in Croatia in the light of major reform tendencies in OECD countries. Croatian Med J 1995;36:47-54.

2 Sarić M, Rodwin VG. The once and future health system in the forme Yugoslavia: myths and realities. J Public Health Policy 1993;14:220-37.

Hebrang A. Reorganization of the Croatian health care system. Croatian Med J 1994;35:130-6.

Orešković S, Kuzman M, Budak A, Vrcić-Keglević M, Ivanković D. Doctor in the house: trends in GPs home visiting in Croatia 1990-1995 compared to current trends in USA and UK. Coll Antropol 1997;21:595-608.
5 Mastilica M, Chen M-S. Health care reform in Croatia: the consumers' perspective. Croatian Med J 1998;39:256-66.

6 Mastilica M, Bozikov J. Out-of-pocket payments for health care in Croatia: implications for equity. Croatian Med J 1999;40:152-9.

7 Chen M-S, Mastilica M. Health care reform in Croatia: for better or for worse? Am J Public Health 1998;88:1156-60.

8 Mastilica M, Babić-Bosanac S. Citizens' views on health insurance in Croatia. Croatian Med J 2002;43:417-24.

9 Maarse H. Cost containment in health care: a brief overview. Antidotum Supplement 1995;1:56-65.

10 Vienonen M. Overview of the principles in health care reforms on the European scene. Antidotum Supplement 1995;1:107-10.

11 World Health Organization. European health care reforms: analysis of current strategies. Copenhagen: WHO Regional Office for Europe, 1996.

12 World Health Organization. European health care reforms: The Ljubljana charter on reforming health care. Copenhagen: WHO Regional Office for Europe, 1996.

13 Stewart AL, Hays RD, Ware JE. The MOS short-form general health survey: reliability and validity in a patient population. Med Care 1988;26:724-35.

14 Sixma HJ, van Campen C, Kerssens II, Peters L. OUOTE-health care services: quality of health care services from the user's perspective. Utrecht: Netherlands Institute of Primary Health Care, 1996.

15 Mastilica M. Health inequalities and health system change in former Yugoslavia. Int J Health Sci 1992;3(3-4):195-203.

16 Mastilica M. Health and social inequities in Yugoslavia. Soc Sci Med 1990;31:405-12

17 Béland Y, Bailie L, Page J. Statistics Canada, Croatian Ministry of Health, and Central Bureau of Statistics: a joint effort implementing the 2003 Croatinn aduthealth survey. Procelings of the American Sintistical Ass Croatian adult health survey. Proceedings of the American Statistical Associction meeting, survey research methods. Toronto: American Statistical Associa-
tion, 2004 .

\title{
Commentary: Patients' empowerment: the East side story
}

\section{Piotr Mierzewski}

Department of

Health and of the

Partial Agreement

in Social and Public

Health Field,

Directorate General

III-Social

Cohesion, Council

of Europe, 67075

Strasbourg-Cedex,

France

Piotr Mierzewski

administrator

piotr.mierzewski@ coe.int
The report by Mastilica and Kušec on citizens' dissatisfaction with the Croatian healthcare system ${ }^{1}$ could have also been set in almost any other country in transition. The transition from "real socialism" to "real prices" has been more difficult and painful than expected. Socialism has become a bad concept-and so have social concerns. In reaction to the previous totalitarian regime, commanding and controlling all social systems, the state has withdrawn from many social responsibilities. This has enabled various interest groups-doctors among them-to shape public opinion.

The public was also largely shaped by the legacy of "Homo sovieticus"-a passive, obedient citizen who trades freedom for safety and who is void of personal initiative and self determination, a citizen who expects, even demands, everything from the state. The forced transition to "Homo economicus" found many citizens who did not fully understand the rules of the new competitive environment feeling helpless. Ironically, "soviet" translates into "the people's council"-a body of direct democracy.

It is a symbolic paradox that social solidarity was among the first victims of the victory of the "Solidarity" (Solidarnosc) movement in Poland, as it was in many other states. Populations expected that universal access to free health services would remain after the transition, and felt betrayed when the market oriented reforms could no longer guarantee it. The social environment for citizens' empowerment was difficult in these new states for several reasons-lack of support from non-existing consumer movements, no tradition of organised lobbying, risk of reliance on funding from the pharmaceutical industry; failure to recognise conflict of interest as a serious issue, and, here and there, corruption. For many politicians, patients' empowerment and citizens' participation were seen as a luxury of wealthy nations-another "imported issue," like feminism or gay marriages.

Despite the rhetoric, there is still not enough noise about "choice and voice."' These issues are not reflected in the extremely useful World Health Organization's "health in transition" reports. In the reports on nine new "post-Soviet" members of the European Union the word empowerment doesn't appear at all; patients' rights are absent from three reports and mentioned only as short references to existing laws in five; and citizens' participation appears only in the report on Slovenia.

How do we get from the diagnosis to deeds? Empowerment means restoring a fair balance of power-but power is never given, only taken (Oreskovic. "The patient in the information age," presented at the fourth European Forum Gastein, 2001). An awakening of the silent majority might be stimulated by the three I's-information, involvement, and instruments. Governments may wish to adopt the comprehensive policy framework for "health democracy" elaborated in the Council of Europe recommendation on the development of structures for citizen participation in decision making processes affecting health care. ${ }^{3}$ A good first step for governments might be to stimulate public debates by commissioning inquiries and publishing reports on citizens' involvement in health care.

There is also much to do at the European level: reactivating WHO's "European partnership for patients' rights and citizens' empowerment"; promoting twinning of non-governmental organisations between the new and the old EU member states; establishing professional lobbying structures in Brussels; supplementing the existing "impact assessments" approach by measuring the impact on patients' and citizens' roles; and adding a patients' rights and 
empowerment component to the existing country profiles that are being published by different organisations (such as "health in transition").

The recent votes in France and the Netherlands against the European Constitution showed that the "democratic deficit" is not just the concern of the new member states. A democratic revolution should become an integral part of the ongoing healthcare reforms. WHO supports this process, since "participation" is one of the guiding values of the new "health for all" policy framework.

The Solidarity movement, glasnost, and perestroika contributed to the European political transition of the 1990s. We now again need social solidarity-"health glasnost," with informed patients in the lead role, and "health perestroika," which will allow the current binding instruments to grow (including patients' rights and citizens' empowerment). ${ }^{4}$ In the emerging European healthcare systems patients and citizens refuse to play Cinderella; they demand a new play in which they can participate as co-creators. Lessons from the "East side story" could help create the "empowered europatient story."

1 Mastilica M, Kušec S. Croatian healthcare system in transition, from the perspective of users. BMJ 2005;331:223-6.

2 Saltman RB. Dimensions of citizen involvement in health care. Eurohealth 2000;6(1):22-5.

3 Council of Europe. The development of structures for citizen and patient participation in the decision-making process affecting health care. Strasbourg: CoE, 2000 (available from www.coe.int/T/E/Social Cohesion/ bourg: CoE, 2000 (available

Health/Recommendations/)

4 Francke R, Hart D. Burgerbeteiligung im Gesundheitswesen. Baden Baden: Nomos Verlaggessellschaft, 2001.

\section{Ethics and the structures of health care in the European countries in transition: hospital ethics committees in Croatia}

\section{Ana Borovečki, Henk ten Have, Stjepan Orešković}

Hospital ethics committees are a recent phenomenon in countries in transition. Croatia's example shows they are staffed mainly by older doctors with no specialist knowledge of ethical issues. The importance of professional relationships and the educational function of ethics committees have been ignored

Healthcare structures, organisations, and institutions have ethical characteristics that are about relationships. These groups are composed of individuals and groups of people with moral obligations. Healthcare structures embody particular organisational cultures that, good or bad, affect people and reflect values. Also, healthcare structures have certain purposes, and they can be evaluated and held accountable whether or not they fulfill their purposes, particularly those affecting and effecting health care. For these reasons, healthcare structures have ethical attributes, and ethical analysis of the healthcare system could be performed. ${ }^{1}$

We use hospitals ethics committees in Croatia to explore the issues connected with structural ethics in healthcare institutions in the countries in transition, and we present it as an example that applies also to other countries in transition. We chose hospital ethics committees because we believe that such an analysis can explain structural ethics issues in a healthcare system.

\section{Hospitals and structural ethics}

Hospitals are healthcare structures made of intricate webs of relationships between people. They have attributes relevant to ethics: they promote values embodied in medical ethics, reinforcing certain kinds of behavior and discouraging transgressions. Hospitals create and promote ethical cultures within their walls. Hospitals have purposes: they protect the wellbeing of patients, foster their healing process, and help patients and their families to cope with disease. On the basis of these purposes, hospitals have responsibilities towards patients and their families. Observing how hospital ethics committees function makes it possible to "read" a hospital. Hospitals and hospital ethics committees are part of the patchwork of a healthcare system, as are the other institutions and organisations. Thus by observing the work of hospital ethics committees one can tell a lot about the ethical climate of the healthcare system itself.

\section{European countries in transition, ethics, and healthcare structures}

Countries in transition in central, eastern, and southeastern Europe have a similar path of development and historical background. ${ }^{2}$ The healthcare structures in countries in transition were regarded as health factories. The number of beds, the number of patients processed, the level of technical sophistication in these healthcare factories were most important in evaluations of their work. Little if any attention was paid to the age, personal characteristics, religious beliefs, and gender differences of patients or to ethical problems that arose in the process of providing health

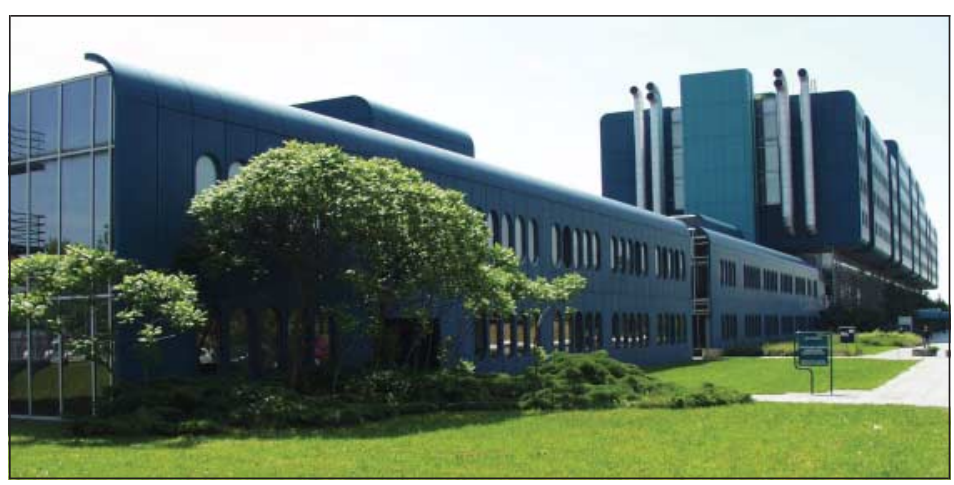

Ethics comes to Croatia's former healthcare factories 